Portland State University

PDXScholar

1974

\title{
The Frequency of Retroflex /R/ Production in Elementary School Children
}

Vicki Barna Wood

Portland State University

Follow this and additional works at: https://pdxscholar.library.pdx.edu/open_access_etds

Part of the Speech and Hearing Science Commons, and the Speech Pathology and Audiology Commons

Let us know how access to this document benefits you.

\section{Recommended Citation}

Wood, Vicki Barna, "The Frequency of Retroflex /R/ Production in Elementary School Children" (1974). Dissertations and Theses. Paper 2272.

https://doi.org/10.15760/etd.2270

This Thesis is brought to you for free and open access. It has been accepted for inclusion in Dissertations and Theses by an authorized administrator of PDXScholar. Please contact us if we can make this document more accessible: pdxscholar@pdx.edu. 
AN ABSTRACT OF THE THESIS OF Vicki Barna Wood for the Master of Science in Speech: With emphasis in Speech Pathology/ Audiology presented May 9, 1974.

Title: The Frequency of Retroflex / $/$ / Production in Elementary School Children.

APPROVED BY MEMBERS OF THE THESIS COMMITTEE:

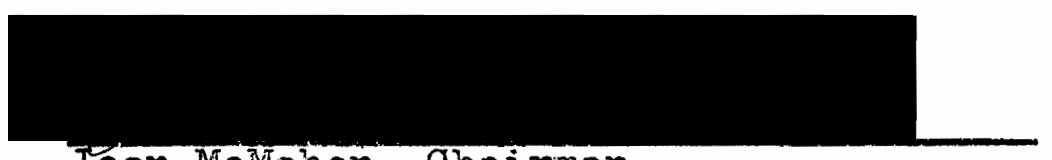

Joan McMahon, Chairman
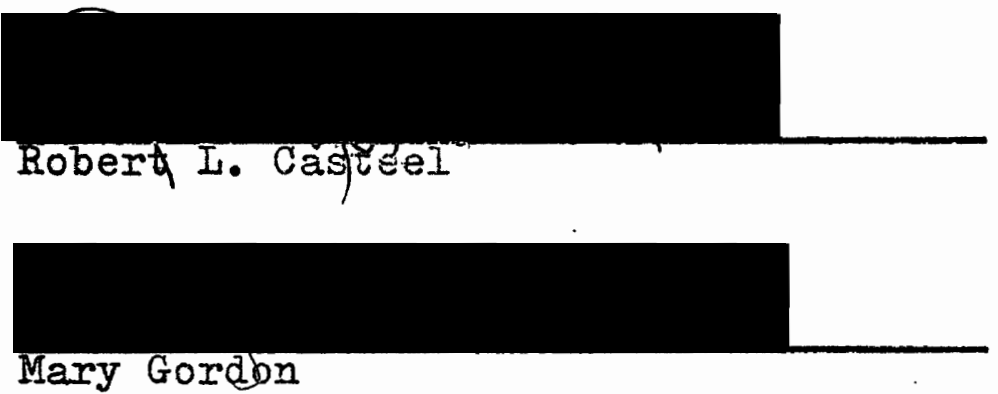

In articulation treatment and diagnosis, it is essential to possess a thorough knowledge of what is "normal" as well as what is "defective" articulation. The / $r /$ phoneme is one of the most frequently occurring and most commonly defective sounds. There are two different tongue positions for the / $/ \mathrm{l}$ phoneme described in the literature (retroflex and central hump), with many assumptions about which tongue position is "normal" or "most common." None of these assumptions, however, are based on empirical data. 
The purpose of this study was to provide some normative data regarding which of the two tongue positions is most common in children who have learned to produce the $/ \mathrm{r} /$ phoneme normally with no clinical assistance. Six research questions were posed: (1) Do children produce the $/ r /$ phoneme more commonly with retroflex or central hump tongue position? (2) Are there sex-related differences? (3) Are there differences in tongue position when the $/ r /$ is used as a consonant or vowel? (4) Are there differences in tongue position when the vocalic/r/ is stressed or unstressed?. (5) Are there differences in tongue position relating to the position of the / $/$ phoneme within a syllable? (6) Does phonetic context affect the tongue position of the /r/ phoneme?

Three hundred white children, 150 males and 150 females, ranging in age from nine to twelve years, were instructed to produce twelve verbal stimuli containing $/ r /$ allophones in various positions within words. Three samples of phonetic context were included in the stimuli. Using a flashlight, the examiner looked into the subject's mouth and made a judgment about tongue position for each response.

The first two research questions were presented in the form of four null hypotheses, and were tested using Chi Square analysis. All four hypotheses were rejected, and therefore it was concluded that:

1. The total population of children tended to use 
retroflex tongue position more often than central hump.

2. Male subjects tended to use retroflex tongue position more often, and female subjects tended to use central hump more often.

The remaining research questions were not tested statistically, but the following trends were apparent from the data:

1. There does not appear to be a substantial difference in tongue position between consonant and rocalic $/ x /$ allophones.

2. There does not appear to be a substantial difference in tongue position between stressed and unstressed vocalic $/ r /$ allophones.

3. There does not appear to be a substantial difference in tongue position depending upon the position of the / $r /$ within a syllable.

4. There does appear to be a substantial difference in tongue position between the two phonetic contexts represented in this study.

The findings in this study provide implications for the treatment of articulation disorders of the / $r /$ phoneme as well as for future research. In articulation treatment, clinicians should evaluate each client to determine which tongue position is most efficient for him. Some valuable treatment time may be conserved if retroflex position is 
instructed with male clients, and central hump position with female clients. It is further indicated that if a client is having difficulty with the / $\mathrm{r} /$ in a particular phonetic context, it might prove valuable to instruct in a different tongue position. It is suggested for future studies of this nature that a larger sample of verbal stimuli be utilized, and subjects of different races, economic level, and ages be tested. Further studies also are needed to determine the reasons for the results of this study, since this was not the purpose of the present study. 


\title{
THE FREQUENCY OF RETROFLEX / $/$ / PRODUCTION
}

IN ELEMENTARY SCHOOL CHIIDREN

\author{
by \\ VICKI BARNA WOOD
}

A thesis submitted in partial fulfillment of the requirements for the degree of

\author{
MASTER OF SCIENCE \\ in \\ SPEECH \\ With emphasis in \\ Speech Pathology/Audiology
}

Portland State University

1974 
TO THE OFFICE OF GRADUATE STUDIES AND RESEARCH:

The members of the Committee approve the thesis of Vicki Barna Wood presented May 9, 1974.

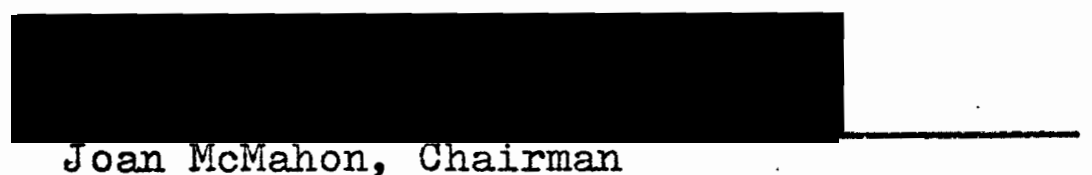

Joan McMahon, Chairman
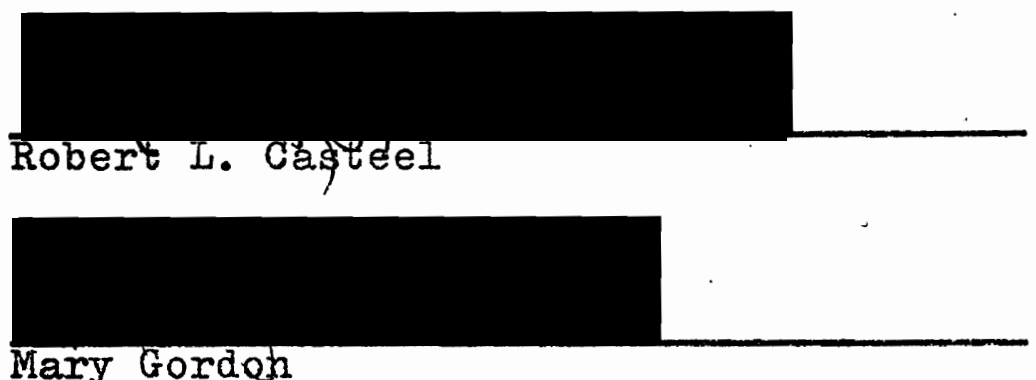

\section{APPROVED:}

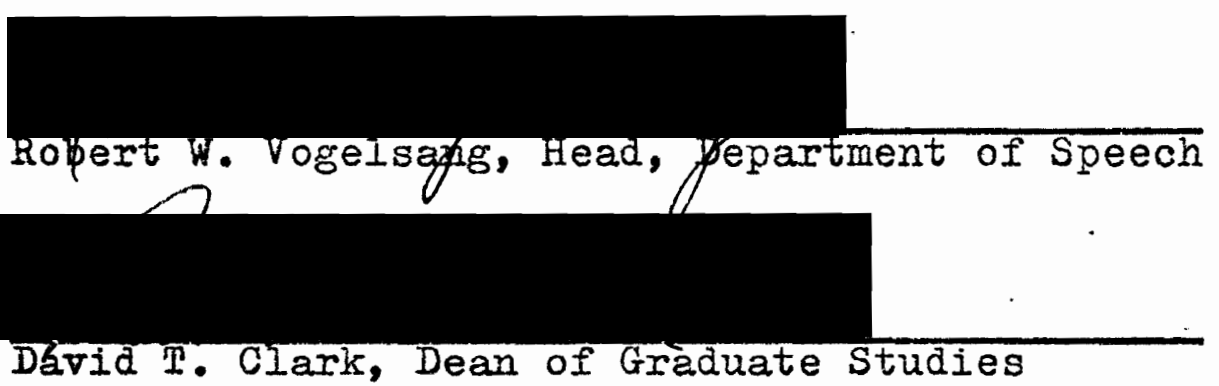

May 17, 1974 


\section{ACKNOWIEDGNENTS}

I wish to express sincere appreciation to:

Mrs. Joan McMahon for her constant encouragement and knowledgeable guidance.

Dr. Robert Casteel and Mrs. Mary Gordon for their helpful comments and suggestions.

Mr. Stephen McFarlane for providing the original inspiration for the study and assisting in the study design.

Mr. Ken Crawford and Mrs. Sue Crawford for providing statistical advice and consultation.

The administration, faculty and participating students of Iake Grove and Bryant schools in Iake Oswego, Oregon. My husband for his help and infinite patience during the writing of this research study. 
TABLE OF CONTENTS

PAGE

ACKNOWLEDGMENTS

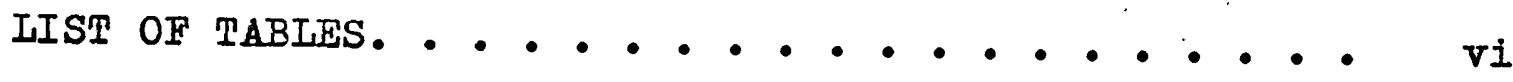
IIST OF FIGURES . . . . . . . . . . . . . . v viii

CHAPTER

I INTRODUCTION AND STATEMENT OF THE PROBLEM • 1

Introduction. • • . . . . . . 1

Purpose of the study: : : : : : : : $\quad 2$

II REVIEW OF THE IITERATURE. • . . . . . 6

Function of the /r/ Phoneme ...... 6

Classification of the /r/ Phoneme: : 9

Tongue Position of the / $r /$ Phoneme: : : 10

III SUBJECTS, METHODS AND PROCEDURES. • • • • 16

Subjects. . . . . . . . . . 16

Methods . . . . . . . . . . 17

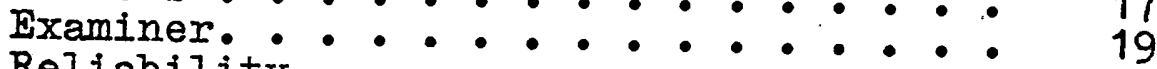

Reliability •. . . . . . . . . 19

Data Analysis ............ 19

IV RESUITS . . . . . . . . . . . . 21

Distribution of Retroflex Quotients . . 23

Total Population

Male and Female Subjects

Distribution of Mixed Response Subjects 26

Total Population

Male and Female Subjects

Consonant and Vocalic'Tongue Position. 
Stressed and Unstressed Vocalic Tongue Position . . . . . . . . . . Position Within the Syllable.... Phonetic Context . . . . . . .

$\mathrm{V}$ DISCUSSION • • • • • • • • • • • • •

Sex Differences. • . • • . . • Distribution of Responses. . . . . Consonant and Vocalic / $/$ / : $:$ : Stressed and Unstressed Vocalic / $/$. . Syllable Position. . . . . . . . Phonetic Context ..........

VI SUMMARY AND IMPIICATIONS . . . . . . 44

Summary. . . . . . •. . . 44

Implications for Clinic and Future

Clinic

Research 


\section{IIST OF TABLES}

TABIE

PAGE

I Opinions of Authors Regarding Tongue Position for Consonant $/ r /$. . . . . . . .

II Opinions of Authors Regarding Tongue Position

for Consonant and Vocalic /r/ Sounds. .

III 2 X 2 Design Used in Testing Hypotheses . . . 21

IV Distribution of Retroflex Quotient Scores . . 24

$\checkmark \quad$ Number and Percentage of Mixed Response Sub-

jects Producing Retroflex Tongue Position

on Each Stimuli . . . . . . . 28

VI Number and Percentage of Retroflex Responses

in Consonant and Vocalic Stimuli for the

Total Population $(\mathrm{N}=300)$. . . . .

VII Number and Percentage of Retroflex Responses

in Stressed and Unstressed Vocalic Stimuli

for the Total Population $(N=300)$. . .

VII Number and Percentage of Retroflex Responses

in Initial, Medial and Final Syllable

Positions for the Total Population ( $N=$ 300). . . . . . . . . .

IX Number and Percentage of Retroflex Responses 
vii

TABIE

PAGE

in Two Phonetic Contexts for the Total

Population $(N=300)$. . . . . . . 


\section{IIST OF FIGURES}

FIGURE

PAGE

1. Distribution of $R Q$ Scores for Total Population ............. 25

2. Distribution of $R Q$ Scores for $\operatorname{Males}(\mathrm{N}=$ 150) and Females $(N=150)$. . . . 27

3. Percentage Retroflex for Each Verbal Stimuli in Total Population of Mixed Response. • 29

4. Percentage Retroflex for Each Verbal Stimuli for Males and Females of Mixed Response. 


\section{CHAPTER I}

\section{INTRODUCTION AND STATEMENT OF THE PROBIEMI}

\section{Introduction}

When studying any area of defective speech or language, it is essential to possess a thorough knowledge of what is meant by "normal." Until the ranges of normalcy are defined, a thoughtful and responsible speech correction program will be unlikely.

The majority of speech disorders encountered by speech clinicians in the public schools are in the area of articulation disorders. In articulation treatment, one of the most common procedures used is that of phonetic placement (Berry and Eisenson, 1956; Van Riper, 1963). Based upon "observations of what most people do to articulate the sounds they speak," (Berry and Eisenson, 1956) the client is provided with diagrams and descriptions of appropriate tongue and lip placement and jaw opening. The clinician often models the correct placement of the articulators, sometimes with the aid of a mircor. Various instruments, such as tongue depressors, can be used to manipulate the client's tongue. Obviously, the clinician must be familiar with the mechanics of articulation of the various speeoh sounds in order to 
instruct their clients.

It is especially important for speech clinicians to be aware of the physiological production of the $/ \mathrm{r} /$ phoneme, because in at least two studies (Hall, 1938; Roe and Milisen, 1942) the / $r /$ was reported as one of the ten most frequently misarticulated consonants in school children, and Van Riper (1963) considered the $/ r /$ as one of the four most commonly defective consonants.

Another justification for the intensive study of $/ \mathrm{r} /$ is its frequency of occurrence. Travis (1931) found that the $\mid r /$ was the third most frequently occurring consonant. Henrikson's study (1948) yielded approximately the same results. If the preceding studies had included in their data the r-colored vowels, the results would have undoubtedly reflected much higher frequencies.

In summary, the knowledge of the mechanics of articulation, especially in such a frequently occurring and frequently misarticulated phoneme as $/ r /$, is very important when instituting articulation modification.

\section{Purpose of the Study}

The purpose of this study was to investigate the tongue positions used for the production of the /r/ phoneme. Most of the American English phonemes are described as having only one major articulatory position which is used by the overwhelming majority of speakers. The $/ r /$ phoneme, 
however, is commonly described as having two distinctly different methods of production. These two methods shall be referred to hereafter in this study as: 1) the retroflex, and 2) the central hump, both of which specifically describe tongue position.

In both methods of articulation, according to Fisher (1966), the "central part of the tongue is tensed and raised toward the palate." Fisher further stated that the difference between the two tongue positions lies in the tongue tip. The tongue tip in the retroflex position she reported as being "lifted toward (but not touching) the palate," and in the central hump position she reported the tongue tip as being "draw back somewhat from the lower teeth."

The transcription $/ \mathrm{r} /$, in this study, was used to symbolize the whole phoneme, or "family of sounds none of which is distinctly different from the other" (Ieutenneger, 1963). Particular attention will be paid to the $/ x /, / 3 /$, and / $/$ / allophones, or "individual, nondistinctive sounds which comprise a phoneme" (Leutenneger, 1963).

The literature regarding the tongue positions of the /r/ phoneme is voluminous. Most authors reviewed who described tongue position expressed an opinion about which position (retroflex or central hump) he felt to be most common. However, none of the opinions given by any of the authors were based on empirical data.

This study was designed to determine the physiological 
production of the $/ x /$ phoneme, with specific reference to tongue position, in a large group of white, elementary school chilaren who have never received clinical speech services and have acoustically "normal" / $/$ phonemes.

This study endeavored to answer the following questions:

1. Do children produce the $/ x /$ phoneme more commonly with retroflex or central hump tongue position?

2. Are there sex-related differences in tongue position?

3. Are there differences in tongue position when the $/ x /$ is used as a consonant or vowel?

4. Are there differenees in tongue position when the vocalic / $r /$ is stressed or unstressed?

5. Are there differences in tongue position relating to the position of the $/ r /$ phoneme within a syllable?

6. Does phonetic context affect the tongue position of the $/ r /$ ?

The four research hypotheses to be tested by this study are presented in the form of the null hypothesis.

Hypothesis (I): The number of children of both sexes using retroflex tongue position is equal to the number of children using central hump tongue position.

Hypothesis (II): The number of male subjects using retro- 
flex tongue position is equal to the number of male subjects using central hump tongue position.

Hypothesis (III): The number of female subjects using retroflex tongue position is equal to the number of female subjects using central hump tongue position.

Hypothesis (IV): The number of male subjects using retroflex tongue position is equal to the number of female subjects using retroflex tongue position. 
CHAPTER II

REVIEW OF THE IITERATURE

The / $/$ / phoneme has been one of the most variously described phonemes in the English language. There have been wide differences of opinion regarding the function, classification and physiological production of this phoneme.

\section{Function of the /I/ Phoneme}

In dealing with the function of $/ r /$, a common practice has been to make a distinction between the $/ r /$ consonant allophone which functions as an initial, medial or final sound in relation to the word in which it occurs, and the r-colored vowels, transcribed $/ 3 /$ and $/ \boldsymbol{s} /$ (stressed and unstressed, respectively) by the vast majority of linguists and speech scientists (Eisenson, 1968; Fairbanks, 1960; Fisher, 1966; Gray, 1971; Kantner and West, 1960; Nemoy and Davis, 1954; Potter, et al., 1966; Thomas, 1958; Wise, 1957). These were the methods of transcription utilized in the widely-used reference A Pronouncing Dictionary of American English (Kenyon and Knott, 1953). An example of an initial consonant (also called prevocalic) would be red; a medial consonant (intervocalic), Very; a final consonant (postvocalic), car; a stressed vowel, bird; and an unstressed 
vowel, mother.

According to Thomas (1958), all normal speakers of English pronounce the initial / $/$, almost all pronounce medial $/ x /$, and over two-thirds pronounce final $/ r /$. Speakers of General American dialect pronounce all three positions of the consonant $/ r /$.

Carrell and Tiffany (1960) recognized no "medial" consonant position, and described the consonant $/ r /$ as either initiating or terminating a syllable. This emphasis upon the relationship of a sound to its syllable, instead of its position within a word, was first stressed by Stetson (1951). Stetson listed four types of syllables: ovo (a vowel syllable released and arrested by the chest muscles); CVO (a syllable released by a consonant and arrested by the chest muscles); OVC (a syllable released by the chest muscles and arrested by a consonant); and CVC (a syllable released by a consonant, and arrested by a consonant). Based on Stetson's theory, a CVO syllable containing / r/ would be raw, an OVC syllable containing / $r /$ would be are, and a CVC syllable containing two / $r /$ phonemes would be rear. An OVO syllable would simply consist of the /3/ or / / vowels alone.

Several authors further limited the function of the consonant / $r$ / to only prevocalic (Curtis and Hardy, 1959; Hibbitt and Norman, 1964; Hultzen, 1950; Leutenneger, 1963). They considered postrocalic / $r /$ as a vowel element of a 


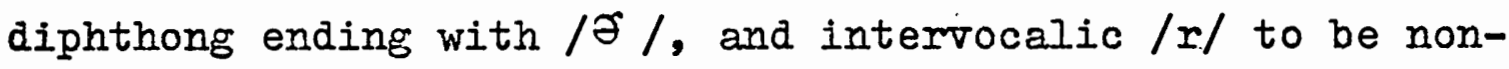
existent except in a few words such as arrow, which they described as containing both the unstressed vocalic and the consonant glide, and which they transcribed as / $/ 2 \gamma \mathrm{ro} /$. Curtis and Hardy (1959) justified their classification of the postrocalic $/ r /$ as a vocalic element because in their analysis of misarticulated / $/$ sounds they noted that "the sounds substituted for the postrocalic /r/ were always vowels, and were the same vowels in general as those substituted for $/ 3 /$ and $/ \sigma /$ which are universally accepted as being vowels."

Another study which added credence to the "prevocalic $\mid r /$ only" theory was that of Lehiste (1964). In this study, spectrographic analysis was utilized to describe the acoustic characteristics of some initial, medial and final allophones of / $r /$ in Midwestern American English. The results indicated that there was enough similarity in formant structure between $/ 3 /$ as a syllable nucleus and the sounds referred to as syllabic and consonantal allophones of / $/$ in the noninitial position, to justify considering them all as allophones of one phoneme. The one allophone that was always clearly distinguishable from all others. was the initial / $/$, which had relatively lower positions for the first three formants.

In summary, the overwhelming majority of phoneticians recognized that the consonant $/ r /$, in at least one position, 
serves a distinctly different function than the syllable nucleus $/ 3 /$ or $/ \partial /$. Only two sources were found which transcribed the /3/ or / / / as / $/ 2$ / (Hockett, 1958; Kurath, 1964).

It is not the purpose of this writer to promote any one theory regarding the function of the $/ x /$ as consonant or vocalic, but rather to incorporate all possibilities into the experimental design.

\section{Classification of the /r/ Phoneme}

The consonant / $I /$ is most often classified as a glide (Bronstein, 1960; Carrell and Piffany, 1960; Cromwell and Van Dusen, 1969; Curtis and Hardy, 1959; Hahn, et al., 1952; Hanley and Thurman, 1962; Kenyon, 1969; Levy, et al., 1955; Ieutenneger, 1963; Prator, 1957; Van Riper and Irwin, 1958). A glide was defined by Kantner and West (1960) as a "sound produced by an unintermpted movement of the articulatory mechanism from the position of one sound to that of another."

The / I/ has been called a fricative, or "consonant sound formed and produced by forcing the voiced or voiceless breath through a narrow opening . . " (Cromwell and Van Dusen, 1969). Those who upheld this classification were: Barnes, 1946; Heffner, 1953; Jones, 1958; Nemoy and Davis, 1954. Frequently the $/ r /$ has been described as having fricative qualities only when following tongue-tip consonants (Eisenson, 1968; Fisher, 1966; Gray, 1971; Kantner and 
West, 1960; Kenyon, 1969; Thomas, 1958; Wise, 1957).

The third common classification of / $r /$ was that of a semi-vowel or Iiquid (Eisenson, 1968; Fairbanks, 1960; Hockett, 1958; Iuchsinger and Arnold, 1965; Thomas, 1958; West and Ansberry, 1968). Cromwell and Van Dusen (1969) defined a semi-vowel as: "a speech sound of vowel quality used as a consonant."

\section{Tongue Position of the /r/ Phoneme}

Iiterature regarding the tongue position used in the $|r|$ phoneme was very inconclusive. The references cited were not in any way meant to be exhaustive, but they do represent a wide variety of opinion.

All of the references gave basically similar descriptions of the two possible tongue positions, even though they were not all referred to as "retroflex" or "central hump," as was done in this study.

It was generally agreed that the acoustic effect of these two tongue positions was nearly identical (Hockett, 1958; Kenyon, 1969; Thomas, 1958; Wise, 1957).

Hibbitt and Norman (1964) and Gray (1971) maintained that the retroflex position was the only tongue position used in both consonant and rowel / $r /$ sounds, although Gray admitted that he felt this retroflexion was "nonessential," presumably because it required more effort to achieve the same acoustic effect. 
At the opposite extreme, Hicks (1963) described both consonant and vowel $/ r /$ sounds as being made in the central hump position only.

Several authors did not describe tongue position for /r/ vowels, and described only retroflex position for consonants (Fairbanks, 1960; Fields and Bender, 1949; Iuchsinger. and Arnold, 1965; Nemoy and Davis, 1954; Prator, 1957; Young and Hawk, 1955). Hanley and Thurman (1962) and West and Ansberry (1968) stated that both retroflex and central hump positions were normal in the consonant $/ r /$, but again did not mention vowel tongue position.

A widely-held opinion was that both retroflex and central hump positions were normal in both vowel and consonant $/ r /$ sounds, and neither was felt to be more prevalent (Bronstein, 1960; Fisher, 1966; Kenyon, 1969; Ieutenneger, 1963; Thomas, 1958).

Several authors also felt that neither retroflex nor central hump position was more common in consonant / $r /$ sounds (Cromwell and Van Dusen, 1969; Hockett, 1958; Jones, 1958; Potter et al., 1966). They differed in their approach to the vowel allophones. Jones felt the retroflex was the most common position in vowels, Potter et al. felt the central hump was the only position used in vowels, Cromwell and Van Dusen felt the retroflex was the only position used in vowels, and Hockett stated the $/ \partial \mathrm{r} /$ (which he used to symbolize vowels) was always produced in a retroflex posi- 
tion in Midwest America.

Carrell and Tiffany (1960) and Barnes (1946) stated that the retroflex position was the only one used in consonant $/ \mathrm{r} /$. The vowel $/ \mathrm{r} /$ sounds were always produced in central hump position according to Carrell and Tiffany. Levy, et al. (1955), Eisenson (1968), Heffner (1953), Gordon and Wong (1961), Wise (1957) and Hahn (1952) all felt the retroflex was the most common position in consonant $/ x /$ and differed in their opinions about vowels. Levy et al. stated the retroflex was also the most common in vowel $/ r /$ sounds, Eisenson felt the central hump was the only position used in vowel / $/$ / sounds, and Hahn felt the retroflex was the only position used in vowel $/ r /$. Heffner, Gordon and Wong, and Wise all stated neither the central hump nor the retroflex was more common in the / $r /$ vowels.

The mannex of production of consonant / $r /$ sounds depended upon the type of consonant being described, according to Kantner and West (1960). They said the fricative $|x|$, which "tends to occur whenever the sound follows or precedes one of the lingua-dental or lingua-alveolar consonants," was produced in a retroflex manner only. They felt the glide $/ r /$, which occurs before or after vowels, could be produced either in a retroflex or central hump manner, and the back /r/, which ordinarily occurs before or after $/ \mathrm{k} /$ or $/ \mathrm{g} /$, was usually a central hump. The central hump was also described as the 'most common position for 
vowel $/ \mathrm{r} /$ sounds.

The position of the consonant / r/ within a syllable or word was felt to have a bearing on its tongue position, according to Kurath (1964). He stated that a prevocalic $\mid r /$ was always made in a retroflex manner, and a postrocalic $\mid r /$ was always made in a central hump manner. He further stated the vowel / $/$ / sounds could be made either way.

Tables I and II are representations of the opinions of the thirty authors in this literature review regarding tongue position of the / $\mathrm{r} /$ phoneme. Table I includes the views of the eight authors who discussed the tongue position for the consonant $/ r /$ sounds only, and Table II describes the theories of the twenty-two authors who discussed both consonant and rocalic / $/$ / sounds. No author reviewed discussed the tongue position for vocalic /r/ only. Kantner

\section{TABIE I}

OPINTONS OF AUTHORS REGARDING TONGUE

POSITION FOR CONSONANT $/ \mathrm{r} /$

Tongue Position

Number

Percentage

Retroflex only

6

$75 \%$

Retroflex most common

0

0

Central Hump only

0

0

Central Hump most common

0

0

Either position (with neither stated as most common) 


\section{TABLE II}

OPINIONS OF AUTHORS REGARDING TONGUE POSITION FOR CONSONANT AND VOCALIC $/ x /$ SOUNDS

\begin{tabular}{|c|c|c|c|c|}
\hline Tongue Position & $\begin{array}{c}\text { Number } \\
\text { Consonant }\end{array}$ & Percentage & \begin{tabular}{|l} 
Number \\
Vocalic
\end{tabular} & Percentage \\
\hline Retroflex only & 4 & $20 \%$ & 4 & $18.2 \%$ \\
\hline $\begin{array}{l}\text { Retroflex most } \\
\text { common }\end{array}$ & 6 & $30 \%$ & 2 & $9.1 \%$ \\
\hline Central Hump only & 1 & $5 \%$ & 4 & $18.2 \%$ \\
\hline $\begin{array}{l}\text { Central Hump most } \\
\text { common }\end{array}$ & 0 & 0 & 2 & $9.1 \%$ \\
\hline $\begin{array}{l}\text { Either position } \\
\text { (with neither } \\
\text { stated as most } \\
\text { common) }\end{array}$ & 9 & $45 \%$ & 10 & $45.4 \%$ \\
\hline
\end{tabular}

and West (1960) and Kurath (1964) were omitted from the consonant column of Table II because of the way they described tongue positions of consonant $/ r /$ as varying according to the function of the sound or position of the sound within a syllable.

Examination of Table I revealed that of the eight authors who discussed tongue position for the consonant $/ x /$, the majority maintained that the retroflex position was the only position used ( 75 percent). The only other opinion represented was that either position could be used, and neither one was felt to be more common (25 percent).

Some differences between the opinions regarding tongue 
position of consonant and vocalic / $/$ / sounds were tabulated in Table II. A total of 50 percent of the authors felt that the retroflex was either the only tongue position or the most common tongue position for consonants, while only 27.3 percent believed this about vocalic $/ r /$. On the other hand, 27.3 percent agreed that the central hump was the only tongue position or the most common tongue position for vowels, but only 5 percent felt the same way about consonants.

The most popular opinion described for both consonant (45 percent) and vocalic ( 45.4 percent) / $/$ / sounds was that either retroflex or central hump positions could be used, and neither was stated to be more common. 


\section{CHAPTER III}

SUBJECTS, METHODS AND PROCEDURES

\section{Subjects}

A total of 300 subjects, 150 males and 150 females, between the ages of nine and twelve were used. The lower age limit of nine was chosen because a study by Poole (1934) indicated that the $/ r /$ sound is one of the last phonemes to be developed, but is achieved by most children by the age of seven and one-half.

The criteria used in the selection of the subjects were: they must produce acoustically normal / r/ sounds, must consistently pronounce all of the $/ r /$ allophones in all positions (General American dialect), and must never have received clinical speech services of any kind in the past or at present.

In order to determine the normality of the subject's /r/ sounds, a few minutes of conversation was elicited. If no distortion was noticed in conversation, the subject was instructed to name five pictures containing the / $r /$ phoneme in different positions within the word. If these were articulated correctly, the test stimuli were administered to the subject. There were 35 children tested who could not be used in the study because of acoustically imperfect $/ \mathrm{r} /$ 
sounds.

The cumulative record of each child tested for this study was examined to determine whether the child had ever received clinical speech services. There were 25 children who were not accepted because they had received these services.

The subjects accepted were all white, and were obtained from an upper-middle class, suburban, public school district.

\section{Methods}

Each subject was instructed to produce the following verbal stimuli: $/ \mathrm{ra} /, / \mathrm{ri} /, \mid \mathrm{arr} /, / \varepsilon \mathrm{ro} /, / \mathrm{r} /, / \mathrm{ar} /$,

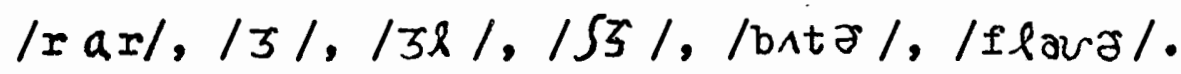

The theories reviewed regarding the function and classification of the $/ r /$ phoneme provided the rationale for the choice of these stimuli. These stimuli place the consonant $/ \mathrm{r} /$ and vowel $/ \mathrm{r} /$ allophones in all possible positions within words, including: consonant $/ x /$ in initial, medial and final position; Curtis and Hardy's (1959) prevocalic / $/ \mathrm{l} /$ and intervocalic / $/ \mathrm{r} /$ combination; Stetson's (1951) four types of syllables; and the / r/ vowels, stressed and unstressed, in isolation and before and after consonants. A small sample of phonetic context was taken by including two rowel contexts in the stimuli $/ r a /, / r i /, / a r /$, and /Ir/. The /a/ vowel is low back, while the / $i /$ and /I/ are 
high front.

The subjects were tested individually in the hallway outside their classroom. Using a flashlight, the examiner looked into the subject's mouth and asked the subject to repeat the stimuli one at a time after the examiner. After each stimuli was repeated, a judgment was made regarding whether the tongue position was retroflex or central hump. If the tongue position was not immediately apparent, the subject was asked to repeat his response. If, after three repetitions, any response could not be determined to be retroflex or central hump, that subject was not used in the study. Nine children were rejected for this reason. The usual cause of rejection was a lack of visibility due to the occlusion of the subject's teeth.

For purposes of analysis, each subject was scored in terms of a Retroflex Quotient (RQ). The RQ is to be defined as the percentage of verbal stimuli in which the retroflex tongue position was used. The RQ was computed for each subject by means of the formula $R Q=\frac{R}{N}$ in which $R$ represents the number of stimuli produced with the retroflex tongue position and $N$ represents the total number of stimuli presented. A RQ score above .50 indicated a tendency to use retroflex tongue position in the stimuli presented. A RQ score below .50 indicated a preference for the use of the central hump tongue position in the stimuli presented. Scores of 1.00 and 0 indicated total retroflex and total 
central hump responses, respectively.

\section{Examiner}

The examiner was a pre-Master's student in speech pathology with over 200 supervised practicum hours in diagnosis and treatment of language and articulation disorders in children.

A second examiner, who was used for the purpose of reliability testing only, was a post-Master's degree speech pathologist with a Certificate of Clinical Competence from the American Speech and Hearing Association, and has had experience as a public school speech clinician and director of a university speech clinic.

\section{Reliability}

Inter-judge reliability was ascertained by both examiners testing thirty ( 10 percent) of the subjects on a random basis. A Phi Coefficient was computed to determine the level of correlation. An inter-judge correlation coefficient of .95 was obtained. Thus, it may be concluded that the examiner was a reliable judge of tongue position.

\section{Data Analysis}

The four null hypotheses were tested using Chi Square analysis.

The other questions dealt with were not tested empiri- 
cally, but were discussed through the use of percentages to show trends. 


\section{CHAPTER IV}

\section{RESUITS}

Four hypotheses were tested. Table III represents the numerical values used in testing the four hypotheses. The four cell totals were obtained by counting the total number of retroflex and central hump responses for all males and all females. The maximum number possible in any cell was 1800 (12 stimuli X 150 subjects).

\section{TABIE III}

$2 \times 2$ DESIGN USED IN TESTING HYPOTHESES

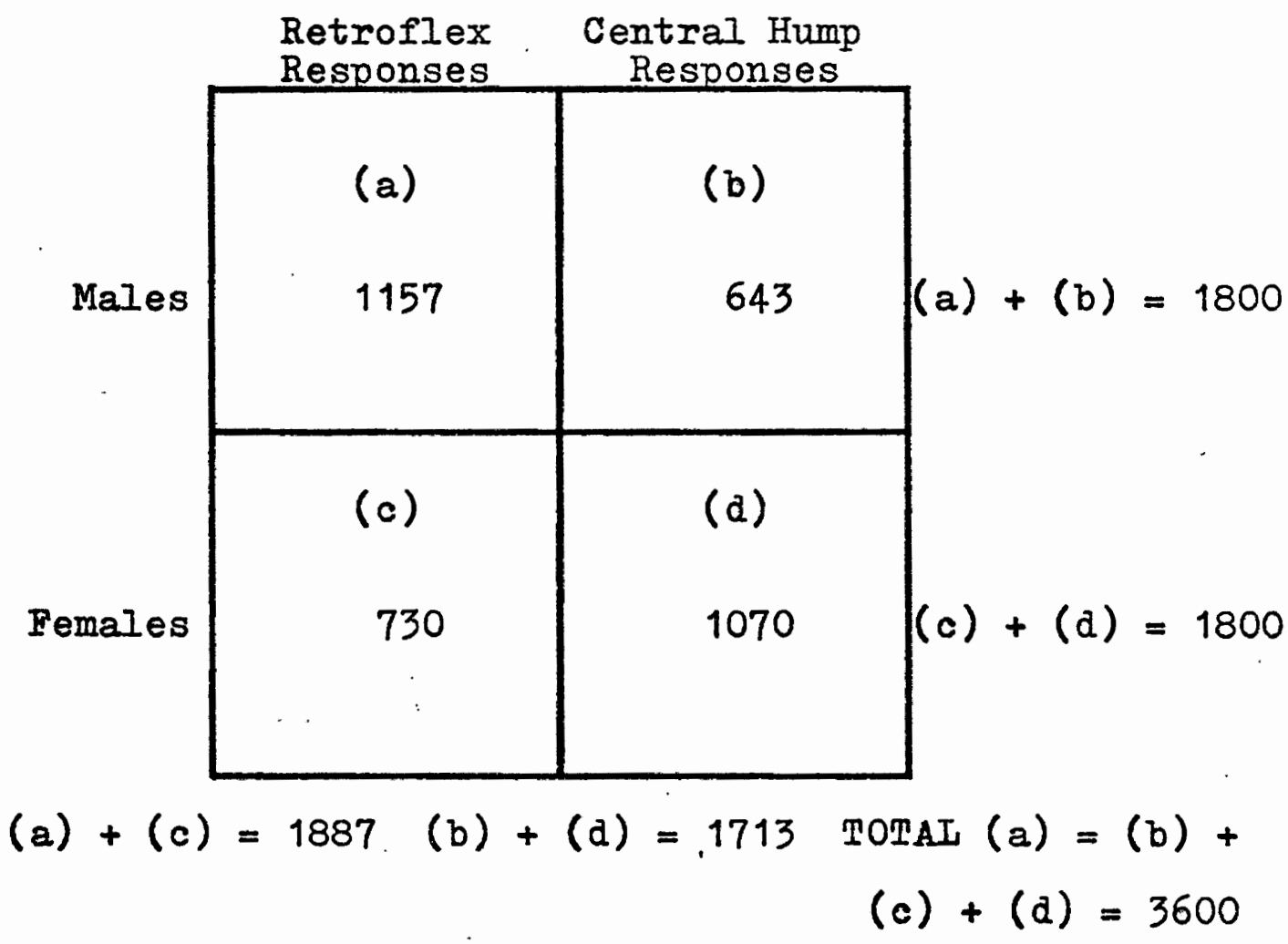


Hypothesis (I): The number of chilaren of both sexes combined using retroflex tongue position is equal to the number of children of both sexes combined using central hump tongue position $(a+c=b+d)$.

Based on the application of the Chi-square Test, a $X 2$ value of 8.410 was found to be significant at the .01 level and therefore it was concluded that the total population of children tended to use retroflex tongue position more often than central hump tongue position. Null hypothesis I therefore was rejected.

Hypothesis (II): The number of male subjects using retroflex tongue position is equal to the number of male subjects using central hump tongue position $(a=b)$.

Based on the application of the Chi-square Test, a $x^{2}$ value of 146.77 was found to be significant at the .001 level and therefore it was concluded that male subjects tended to use retroflex tongue position more often than central hump tongue position. Null hypothesis II therefore was rejected.

Hypothesis (III): The number of female subjects using retroflex tongue position is equal to the number of female subjects using central hump tongue position $(c=d)$. 
Based on the application of the Chi-square Test, a $X^{2}$ value of 64.222 was found to be significant at the .001 level and therefore it was concluded that female subjects tended to use central hump tongue position more often than retroflex tongue position. Null hypothesis III therefore was rejected.

Hypothesis (IV): The number of male subjects using retroflex tongue position is equal to the number of female subjects using retroflex tongue position $(a=c)$.

Based on the application of the Chi-square Test, a $X^{2}$ value of 96.623 was found to be significant at the .001 level and therefore it was concluded that male subjects tended to use retroflex tongue position more often than female subjects tended to use retroflex tongue position. $\mathrm{Null}$ hypothesis IV therefore was rejected.

A fifth statement can be assumed, since it is the converse of null hypothesis IV: Female subjects tended to use central hump tongue position more often than male subjects tended to use central hump tongue position.

\section{Distribution of Retroflex Quotients}

Table IV shows the numerical distribution of the Retroflex Quotient scores for males, females, and the total population. The RQ was computed for each subject by dividing 
the number of stimuli produced with a retroflex tongue position by the total number of stimuli (12).

\section{TABIE IV}

DISTRIBUTION OF RETROFIEX QUOTIENT SCORES

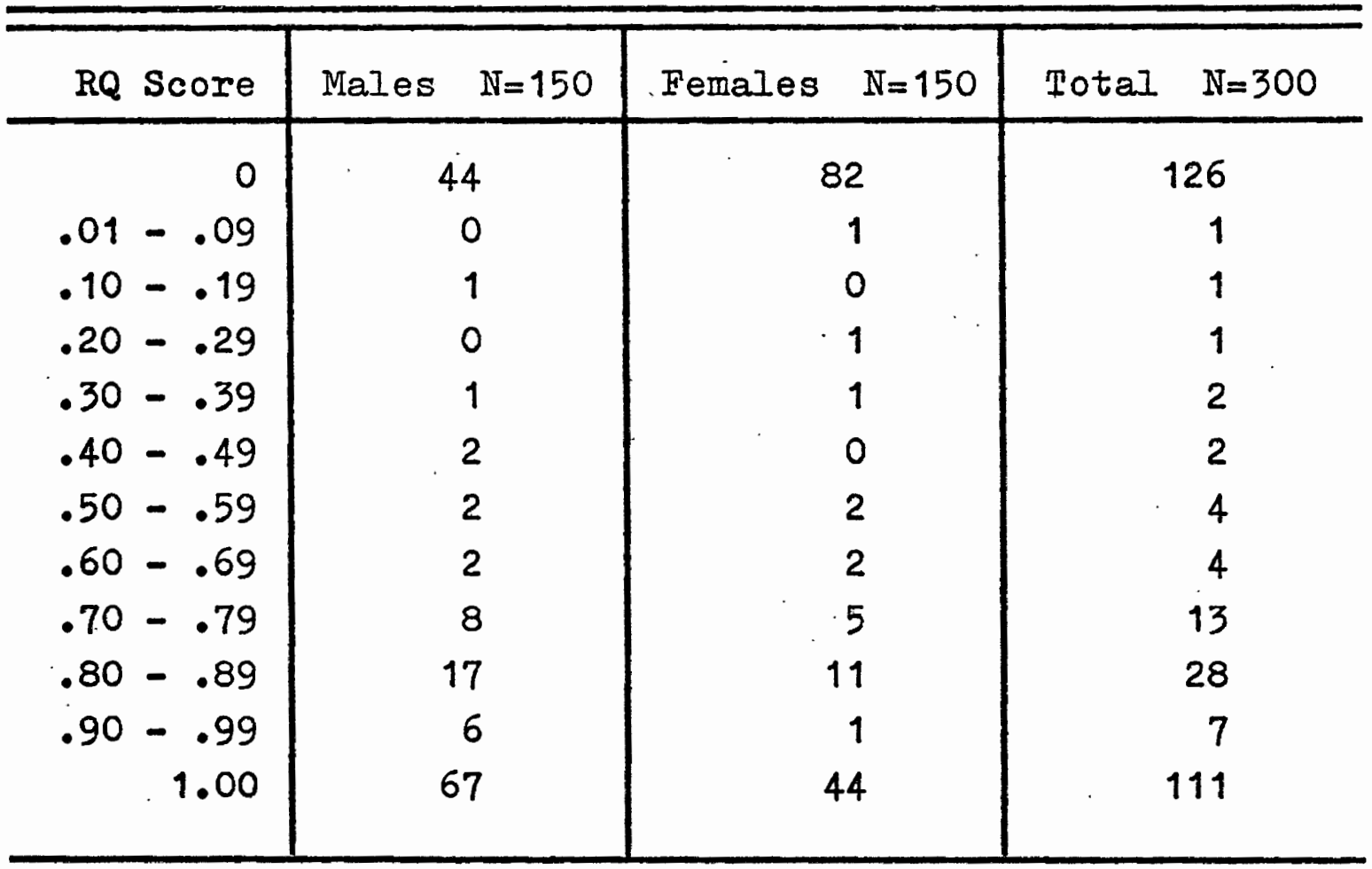

Examination of Table IV revealed that of the 300 subjects, 111 used all retroflex responses, and 126 used all central hump responses. This left 63 subjects who used a combination of both retroflex and central hump responses.

Total Population. Figure 1 indicates the distribution of the Retroflex Quotient scores for the total population. When male and female subjects were combined, a total of 111 subjects ( 37 percent) used retroflex tongue position in all stimuli, 126 subjects (42 percent) used central hump tongue 


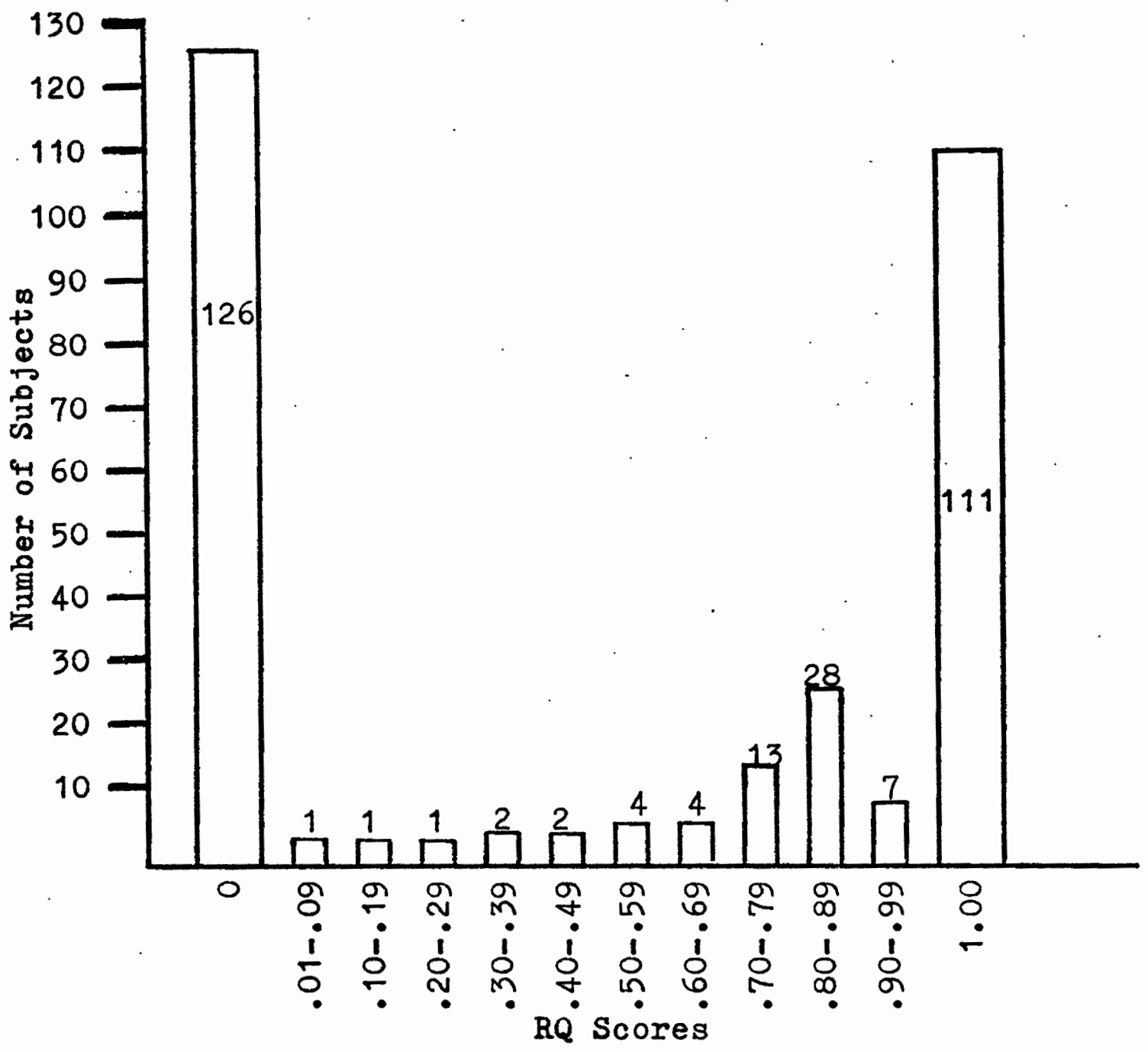

Figure 1. Distribution of RQ scores for total population $(\mathbb{N}=300)$.

position in all stimuli, and 63 subjects ( 21 percent) used a combination of both retroflex and central hump positions.

Male and Female Subjects. A total of 67 male subjects (44.67 percent) and 44 female subjects (29.33 percent) used retroflex tongue position in all stimuli. There were 44 males (29.33 percent) and 82 females ( 54.67 percent) who used central hump tongue position in all stimuli. A combination of retroflex and central hump tongue position was 
used by 39 males (26 percent) and 24 females (16 percent). Figure 2 indicates the distribution of the Retroflex Quotient scores for males and females.

As can be seen by Figure 2, most of the sex differences were found in the number of males and females using all central hump responses, all retroflex responses, or mostly retroflex responses (between .70 and $.99 R Q$ scores). The distribution of the scores ranging from .01 to .69 Retroflex Quotients was almost identical for males and females.

\section{Distribution of Mixed Response Subjeats}

There were 39 males and 24 females who produced a combination of both retroflex and central hump tongue position on the twelve verbal stimuli. Table $V$ describes the number and percentage of retroflex responses for each of the verbal stimuli among these 63 subjects.

When Table $V$ was examined, it was evident that almost all of the central hump responses from the mixed-response subjects arose from the three verbal stimuli /ri/, / $/ \mathrm{ro} /$, and /I $\mathrm{r} /$. The only other stimulus receiving less than 75 percent retroflex responses was / $/ 53 /$. For both sexes combined, there were only 14 total central hump responses on the four stimuli / $a /, / a r \partial /, / a r /$ and $/ r a r /$, and only 32 total central hump responses on the four stimuli $/ 3 /$, $/ 3 l /$, /bnt $\delta /$ and $/ f R a r \gamma /$. It is felt that these results 


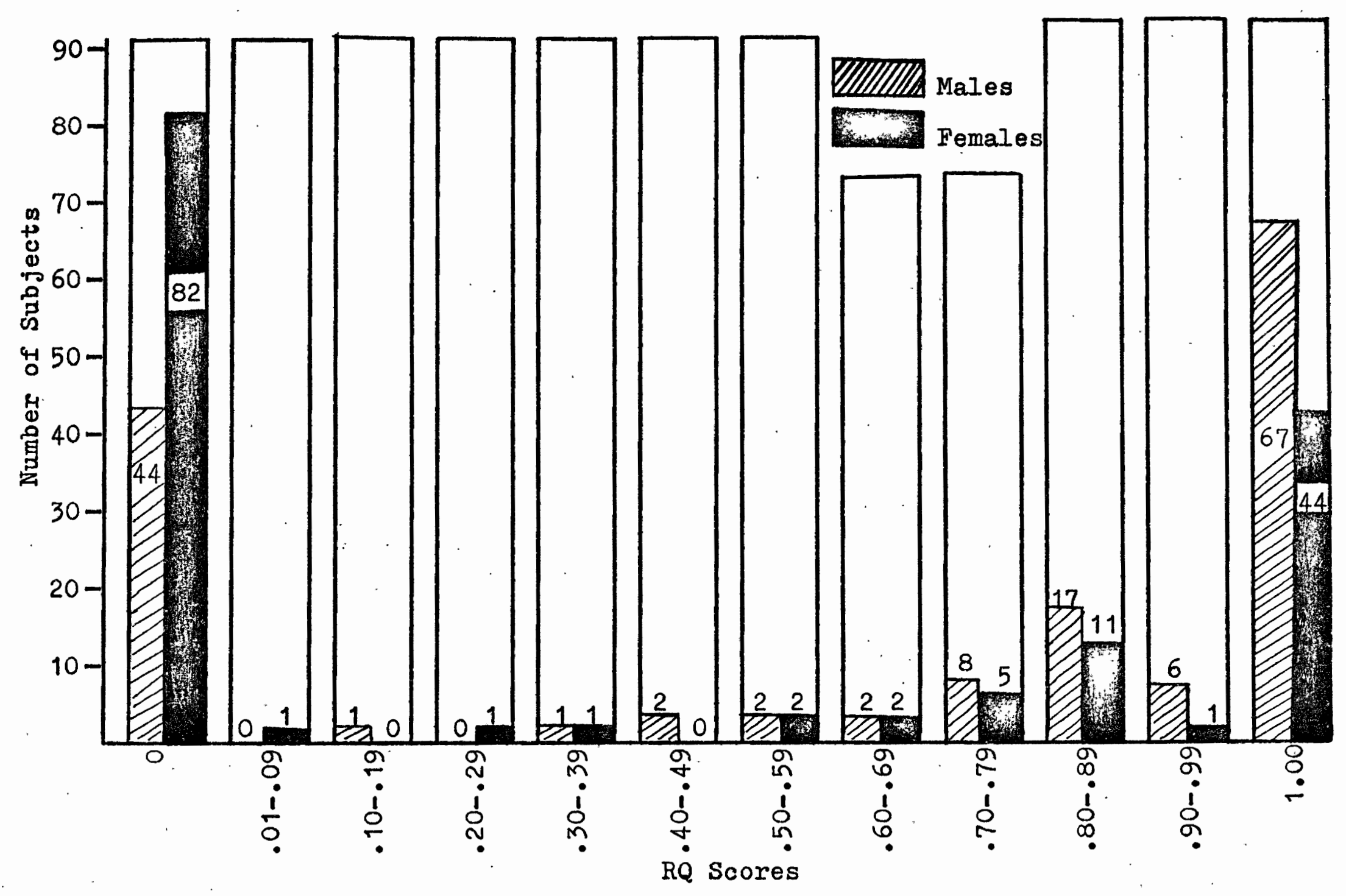

Figure 2. Distribution of $R Q$ Scores for Males $(N=150)$ and Females $(N=150)$. N 


\section{TABLE V}

NUIMBER AND PERCENTAGE OF MIXED RESPONSE

SUBJECTS PRODUCING RETROFIEX TONGUE

POSITION ON EACH STIMUII

\begin{tabular}{|c|c|c|c|c|c|c|}
\hline \multirow[b]{2}{*}{ Stimuli } & \multicolumn{2}{|c|}{ Males $\mathrm{N}=39$} & \multicolumn{2}{|c|}{ Females $\mathrm{N}=24$} & \multicolumn{2}{|c|}{ Total $N=63$} \\
\hline & $\begin{array}{l}\text { Number } \\
\text { Retro. }\end{array}$ & $\begin{array}{l}\text { Percent } \\
\text { Retro. }\end{array}$ & $\begin{array}{l}\text { Number } \\
\text { Retro. }\end{array}$ & $\begin{array}{l}\text { Percent } \\
\text { Retro. }\end{array}$ & $\begin{array}{l}\text { Number } \\
\text { Retro. }\end{array}$ & $\begin{array}{l}\text { Percent } \\
\text { Retro. }\end{array}$ \\
\hline$/ r a /$ & 38 & $97.44 \%$ & 22 & $91.67 \%$ & 60 & $95.24 \%$ \\
\hline /ri/ & 16 & $41.03 \%$ & 10 & $41.67 \%$ & 26 & $41.27 \%$ \\
\hline$/ \operatorname{arz} /$ & 37 & $94.87 \%$ & 22 & $91.67 \%$ & 59 & $93.65 \%$ \\
\hline$/ \varepsilon \mathrm{ro} /$ & 16 & $41.03 \%$ & 6 & $25 \%$ & 22 & $34.92 \%$ \\
\hline |ar| & 37 & $94.87 \%$ & 22 & $91.67 \%$ & 59 & $93.65 \%$ \\
\hline$|\operatorname{Ir}|$ & 3 & $7.69 \%$ & 1 & $4.17 \%$ & 4 & $6.35 \%$ \\
\hline /rarl & 38 & $97.44 \%$ & 22 & $91.67 \%$ & 60 & $95.24 \%$ \\
\hline 131 & 34 & $87.18 \%$ & 20 & $83.33 \%$ & 54 & $85.71 \%$ \\
\hline $13 x \mid$ & 37 & $94.87 \%$ & 20 & $83.33 \%$ & 57 & $90.48 \%$ \\
\hline $153 \%$ & 30 & $76.92 \%$ & 16 & $66.67 \%$ & 46 & $73.02 \%$ \\
\hline$/ \mathrm{b} \wedge t \partial /$ & 35 & $89.74 \%$ & 21 & $87.5 \%$ & 56 & $88.89 \%$ \\
\hline / flav $\sigma /$ & 33 & $84.62 \%$ & 20 & $83.33 \%$ & 53 & $84.13 \%$ \\
\hline
\end{tabular}

are related to phonetic context and will be discussed in the next chapter.

Total Population. The data in Table $\mathrm{V}$ for the total population of mixed response was graphed in Figure 3 . The percentage retroflex on a single stimulus ranged from 6.35 percent on the stimulus /Ir/, to 95.24 percent on the stimuli /ra/ and /rar/. 


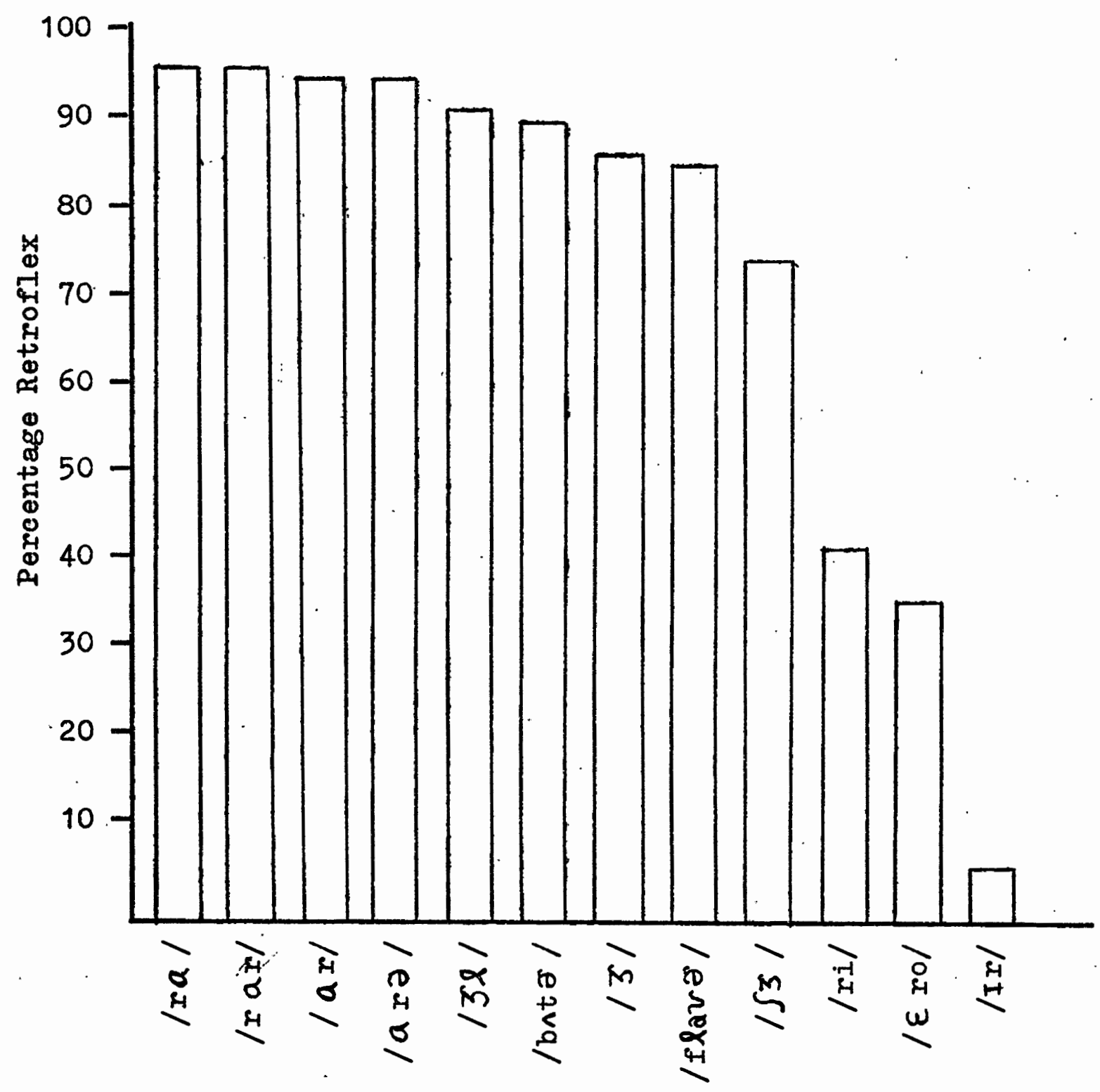

Verbal Stimuli

Figure 3. Percentage Retroflex for Each Verbal Stimuli in Total Population of Mixed Response.

Male and Female Subjects. When male subjects of mixed-response only were considered, the retroflex percentage range was from 97.44 percent on the stimuli /ra/ and /rar/, to 7.69 percent on the stimulus /Ir/. The retroflex percentage range was from 91.67 percent on the stimuli 
/ra/, /rar/, / $a r /$ and /ary/, to 4.17 percent on the stimulus /Ir/, when only the female subjects of mixedresponse were considered. Figure 4 displays the data for males and females from Table $V$ in graph form.

\section{Consonant and Vocalic Tongue Position}

The verbal stimuli were divided into consonant and vocalic / $/$ / categories, and the number and percentage of retroflex responses were computed for each stimulus (Table VI). A mean was then obtained for each category. The stimulus /rar/ was omitted from this analysis because the results on this stimulus (171 retroflex) were virtually the same as on the two stimuli / $r a /$ and $/ a r /$.

\section{TABIE VI}

NUMBER AND PERCENTAGE OF RETROFLEX RESPONSES

IN CONSONANT AND VOCAIIC STIMULI FOR THE TOTAI POPUIATION $(N=300)$

\begin{tabular}{|c|c|c|c|c|c|}
\hline $\begin{array}{c}\text { Consonant } \\
\text { Stimuli }\end{array}$ & $\begin{array}{c}\text { Number } \\
\text { Retroflex }\end{array}$ & $\begin{array}{l}\text { Percentage } \\
\text { Retroflex }\end{array}$ & $\begin{array}{l}\text { Vocalic } \\
\text { Stimuli }\end{array}$ & $\begin{array}{l}\text { Number } \\
\text { Retroflex }\end{array}$ & $\begin{array}{l}\text { Percentage } \\
\text { Retroflex } \\
\end{array}$ \\
\hline$|r a|$ & 171 & $57 \%$ & $|3|$ & 166 & $55.33 \%$ \\
\hline$/ \mathrm{ri} /$ & 137 & $45.67 \%$ & $|3 l|$ & 168 & 56 \\
\hline $\mid \operatorname{arz} /$ & 170 & $56.67 \%$ & $\left|S_{3}\right|$ & 157 & $52.33 \%$ \\
\hline /Ero/ & 130 & $43.33 \%$ & /b^tə / & 167 & $55.67 \%$ \\
\hline |arl & 170 & $56.67 \%$ & /flavr/ & 164 & $54.67 \%$ \\
\hline $\mid \operatorname{Ir} /$ & 137 & $45.67 \%$ & & & \\
\hline Mean & 152.5 & $50.83 \%$ & Mean & 164.4 & $54.8 \%$ \\
\hline
\end{tabular}




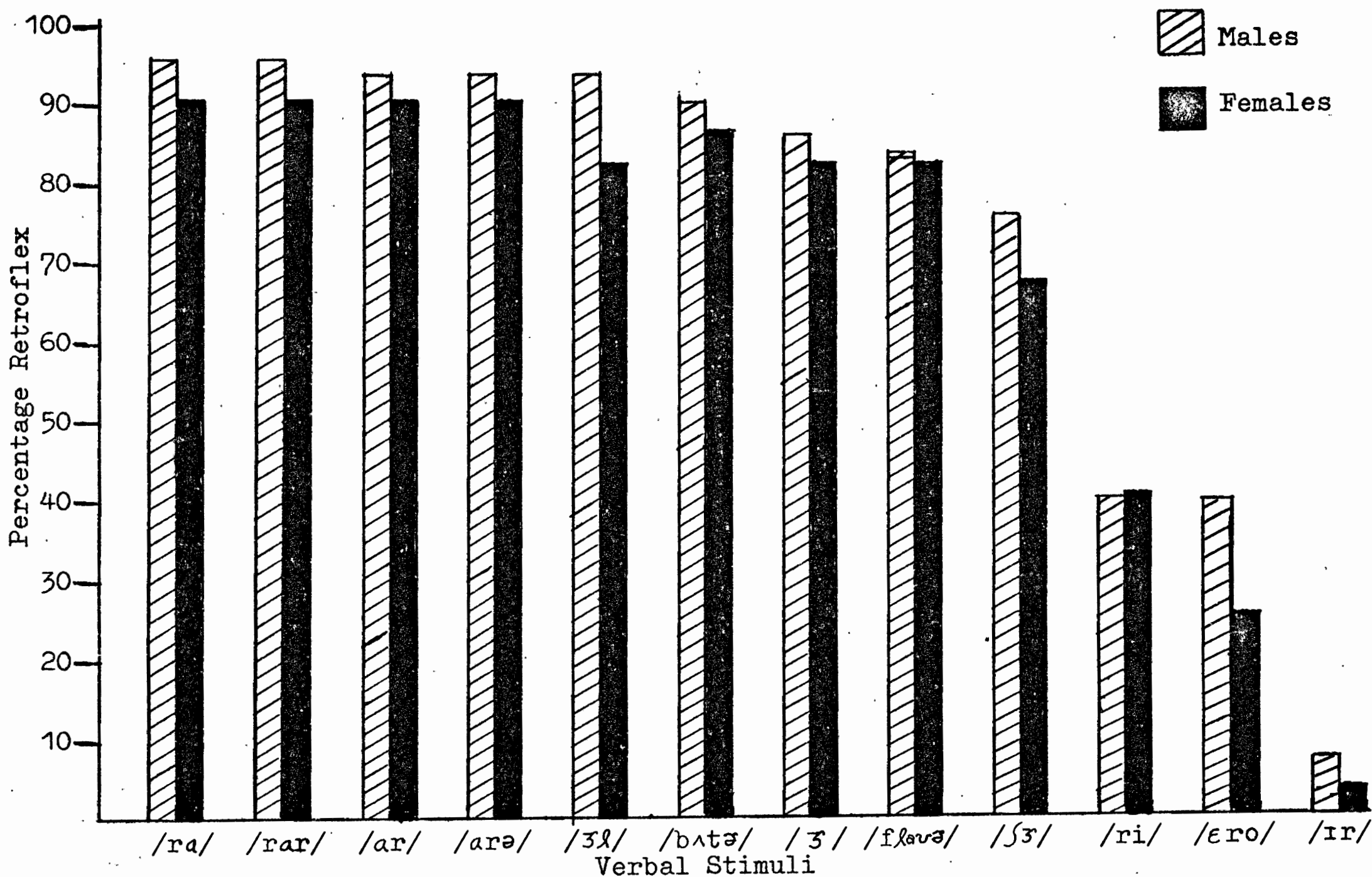

Figure 4. Percentage Retroflex for Each Verbal Stimuli for Males and Females

$\stackrel{w}{\rightarrow}$ 
As indicated in Table VI, the average number of subjects producing retroflex tongue position on the combined consonant stimuli was 152.5 (50.83 percent). The number of retroflex responses in a single consonant stimulus ranged from 130 in the stimulas / $\varepsilon$ ro/, to 171 in the stimulus $/ r a /$. For the combined vocalic stimuli, an average number of 164.4 subjects ( 54.8 percent) produced retroflex tongue position. The range on a single vocalic stimulus was from 157 retroflex responses on the stimulus / $\int 3 /$ to 168 retroflex responses on the stimulus $/ 3 l /$.

The average percentage of retroflex responses on the consonant stimuli was very similar to the average percentage of retroflex responses on the vocalic stimuli. It can be stated that for the limited number of stimuli in this study there does not appear to be a substantial difference between tongue position in vocalic and consonant / $/$ allophones.

\section{Stressed and Unstressed Vocalic}

\section{Tongue Position}

The five vocalic stimuli were divided into stressed and unstressed categories, the number and percentage of retroflex responses were computed for each stimulus, and a mean was obtained for the two categories (Table VII).

The number of retroflex responses in stressed vocalic stimuli ranged between 157 for the stimulus / $53 /$ and 168 for the stimulus /3l/. The mean number of retroflex responses for the three stressed vocalic stimuli was 163.7 
TABLE VII

NUMBER AND PERCENTAGE OF RETROFLEX RESPONSES

IN STRESSED AND UNSTRESSED VOCAIIC STIMULI

FOR THE TOTAI POPUI ATION $(N=300)$

\begin{tabular}{|c|c|c|c|c|c|}
\hline $\begin{array}{c}\text { Stressed } \\
\text { Vocalic Stim. }\end{array}$ & $\begin{array}{l}\text { Number } \\
\text { Retro. }\end{array}$ & $\begin{array}{l}\text { Percent } \\
\text { Retro. }\end{array}$ & $\begin{array}{l}\text { Unstressed } \\
\text { Vocalic Stim. }\end{array}$ & $\begin{array}{l}\text { Number } \\
\text { Retro. }\end{array}$ & $\begin{array}{l}\text { Percent } \\
\text { Retro. }\end{array}$ \\
\hline 131 & 166 & $55.33 \%$ & /bnto / & 167 & $55.67 \%$ \\
\hline$|3 l|$ & 168 & $56 \%$ & /flar $\sigma /$ & 164 & $54.67 \%$ \\
\hline 1531 & 157 & $52.33 \%$ & & & \\
\hline Mean & 163.7 & $54.56 \%$ & Mean & 165.5 & $55.17 \%$ \\
\hline
\end{tabular}

( 54.55 percent). This can be compared to a mean number of 165.5 ( 55.16 percent) retroflex responses for the two unstressed rocalic stimuli. The two unstressed vocalic stimuli received 167 and 164 retroflex responses. For the very small number of stressed and unstressed vocalic/r/ allophones in this study, there did not appear to be any difference in average tongue position.

\section{Position Within the Syllable}

In Table VIII, the stimuli are separated into initial, medial and final position. The number and percentage of retroflex tongue position for the total population was computed for these stimuli, and means were obtained. The stimulus /rar/ was omitted from this analysis for the same reason as in Table VII. The vocalic stimuli /3/, /bato/ 
TABIE VIII

NUMBER AND PERCENTAGE OF RETROFIEX RESPONSES IN INITIAI, MEDIAI AND FINAI SYIIABIE POSITIONS FOR THE

TOTAL POPULATION $(N=300)$

\begin{tabular}{|c|c|c|c|c|c|c|c|c|}
\hline $\begin{array}{l}\text { Initial } \\
\text { Stimuli }\end{array}$ & $\begin{array}{c}\text { Number } \\
\text { Retroflex }\end{array}$ & $\begin{array}{l}\text { Pexcentage } \\
\text { Retroflex }\end{array}$ & $\begin{array}{r}\text { Medial } \\
\text { Stimuli }\end{array}$ & $\begin{array}{c}\text { Number } \\
\text { Retroflex }\end{array}$ & $\begin{array}{l}\text { Percentage } \\
\text { Retroflex }\end{array}$ & $\begin{array}{l}\text { Final } \\
\text { Stimuli }\end{array}$ & $\begin{array}{c}\text { Number } \\
\text { Retroflex }\end{array}$ & $\begin{array}{l}\text { Percentage } \\
\text { Retroflex }\end{array}$ \\
\hline$|r a|$ & 171 & $57 \%$ & $|\operatorname{ara}|$ & 170 & $56.67 \%$ & $|a r|$ & 170 & $56.67 \%$ \\
\hline$/ x i /$ & 137 & $45.67 \%$ & / Ero/ & 130 & $43.33 \%$ & $|\operatorname{Ir}|$ & 137 & $45.67 \%$ \\
\hline $132 \mid$ & 168 & $56: \%$ & & & & $1 \sqrt{3} 1$ & 157 & $52.33 \%$ \\
\hline Mean & 158.67 & $52.89 \%$ & Mean & 150 & 50 & Mean & 154.67 & $51.56 \%$ \\
\hline
\end{tabular}


and / flard / were not used in this table because these stressed and unstressed / $/$ / allophones comprised total syllables.

Table VIII revealed that the three initial position stimuli averaged 52.89 percent retroflex responses, the two medial position stimuli averaged 50 percent retroflex responses, and the three final position stimuli averaged 51.56 percent retroflex responses. For this small sample, it can be concluded that syllable position did not affect tongue position.

\section{Phonetic Context}

A comparison was made between two phonetic contexts for the consonant $/ \mathrm{r} /$ stimali in initial and final position (Table IX). The $/ a /$ is a low back vowel context, and the /i/ and /I/ are high front vowel contexts (relative to tongue placement in the oral cavity).

\section{TABIE IX}

NUMBER AND PERCENTAGE OF RETROFTEX RESPONSES

IN TWO PHONETIC CONTEXTS FOR THE TOTAL POPULATION $(\mathrm{N}=300)$

\begin{tabular}{|c|c|c|c|c|c|}
\hline $\begin{array}{l}\text { Low Back } \\
\text { Phonetic } \\
\text { Context }\end{array}$ & $\begin{array}{l}\text { Number } \\
\text { Retroflex }\end{array}$ & $\begin{array}{l}\text { Percent } \\
\text { Retroflex }\end{array}$ & $\begin{array}{l}\text { High Front } \\
\text { Phonetic } \\
\text { Context }\end{array}$ & $\begin{array}{c}\text { Number } \\
\text { Retroflex }\end{array}$ & $\begin{array}{l}\text { Percent } \\
\text { Retroflex }\end{array}$ \\
\hline$|r a|$ & 171 & 57 & /ri/ & 137 & $45.67 \%$ \\
\hline / ar/ & 170 & $56.67 \%$ & $|\operatorname{Ir}|$ & 137 & $45.67 \%$ \\
\hline Mean & 170.5 & $56.83 \%$ & Mean & 137 & $45.67 \%$ \\
\hline
\end{tabular}


The average number of subjects using retroflex position in the two stimuli with low back phonetic context was 170.5 ( 56.83 percent). The high front phonetic contexts produced an average of 137 retroflex responses (45.66 percent). This data indicates that phonetic context does appear to affect tongue position for the limited sample studied. 
CHAPIER $\nabla$

\section{DISCUSSION}

This study was designed to test empirically a question that has been answered by assumptions in the literature: Which of the two commonly described tongue positions for the / $\mathrm{r} /$ phoneme is used most often by children who have learned to produce this sound normally with no clinical remediation?

In view of the results cited in the foregoing chapter, statistical analysis indicated that when the male and female subjects were combined, the retroflex tongue position tended to be used more often. Each subject produced twelve verbal stimuli. Although the stimuli were chosen in an attempt to provide a sample of $/ r /$ allophones in varied positions and phonetic contexts, only further studies can determine whether or not they were a representative sample.

When the results obtained for the combined male and female population were compared with the opinions appearing in the literature, some similarities were noted. When the opinions of the thirty authors reviewed in Tables $I$ and II were examined, it can be seen that the opinion most often expressed was that either tongue position could be used, without specifying one as more common. Of those who did 
express an opinion, the retroflex was the most often chosen, considering opinions on consonant and vocalic / $r$ combined.

\section{Sex Differences}

When male and female responses were analyzed separately, the results showed that males tended to use retroflex tongue position more often, while females tended to use central hump position more often. No references to sex-related differences in the tongue position of the $/ x /$ phoneme appeared in the literature; therefore, the rejection of nuIl hypotheses II, III and IV was unexpected. Although the main purpose of this study was to determine "what" is the most common tongue position, and not "why," a few theories can be proposed to account for this difference.

A reason to account for the difference may arise from the fact that females tend to achieve precise articulation at an earlier age than males. Templin (1952) stated that "girls reach about 95 per cent correct articulation, probably practically adult articulation, at about seven years, while boys take another year in which to reach the same degree of perfection." Since females produced a greater number of central hump responses in this study, and females, in general, achieve correct articulation before males, it may follow that the central hump position is a more "mature," "precise," or "efficient" tongue posi- 
tion than the retroflex. The results may have been more equal if an older population had been studied, in order to account for the maturation lag.

A second possibility to account for the sex distinction may be related to oral structure deviations between males and females. There may be heretofore undiscovered differences in palate shape or size which would predispose one sex toward a different tongue position.

\section{Distribution of Responses}

Besults showed that of the 300 subjects, 111 used all retroflex responses, 126 subjects used all central hump responses, and 63 used a combination of both retroflex and central hump responses. A question to be considered is: Why did most of the subjects use only one tongue position on all the stimuli, and a minority of the subjects use a combination of both tongue positions? It is possible that the mixed-response subjects had not yet firmly established the usage of one tongue position. This could be an explanation for why fewer females used mixed tongue position than males, since females tend to achieve maturation in articulation before males. This explanation, however, necessitates the assumption that the "mature" articulator of the / $/ \mathrm{l}$ phoneme consistently uses one tongue position. On the other hand, the mixed-response subjects may actualiy have been the most "mature" or "efficient," if we assume they had 
the flexibility to adapt their tongue to the most economical position for the particular context.

As can be seen by Figure 2, the greatest similarity in the distribution of the Retroflex Quotient scores for males and females occurred in the scores ranging from .01 to .69. There were only 15 subjects who fell in this range. There were 48 subjects who fell in the range between .70 and .99, where there was a greater difference between sexes. The fact that this mixed-response population was so heavily retroflex was the reason for rejection of the first null hypothesis. If the number of totally central hump subjects and the number of totally retroflex subjects had been compared statistically, the results may well have favored central hump as the most common tongue position.

The general pattern for the mixed-response subject was to produce most of the stimuli with retroflex position, and three to four of the stimuli with central hump. This fact may provide another reason why there were only 16 percent of the females with mixed tongue position and 26 percent of the males. Since fewer of the females produced all twelve stimuli with retroflex position than males (see Figure 2), there was less opportunity for females to fall into the pattern of mixed-response.

\section{Consonant and Vocalic/x/}

It was concluded in the results of this study that 
tongue position does not appear to be affected by the usage of the $/ r /$ as consonant or vocalic. When these results are compared to the opinions discussed in the literature, a great discrepancy can be noted. When the data on Tables I and II are combined, it is evident that the retroflex is heavily favored as the tongue position for consonant / $/$ by those authors who stated an opinion that one position was used exclusively or more commonly. For vocalic / $/$, a little less than half of the authors felt either position could be used, and the remaining authors were divided evenly between central hump and retroflex positions.

The difference between the results obtained in this study and the opinions of the authors reviewed could have arisen either because of the small number of stimuli used in this study, or because the authors reviewed did not base their opinions on empirical data.

\section{Stressed and Unstressed Vocalic/r/}

From the results of this study it was concluded that there did not appear to be any difference in tongue position between stressed and unstressed vocalic / $/$ allophones. There were no authors discussed in the review of the literature who made any distinction between stressed and unstressed vocalic $/ \mathrm{r} /$.

Sylable Position

The position of the $/ x /$ allophone within a syllable 
did not appear to affect tongue position in this study. Since there were only two examples of initial, medial and final consonant / $\mathbf{r} /$ positions, and only one example of initial and final vocalic / $/$ / positions in the stimuli, these results should be taken cautiously.

Only one author reviewed (Kurath, 1964) discussed the position of the / $/$ within a syllable as affecting the tongue position. Kurath stated that the prevocalic consonant $/ I /$ was always produced with retroflex tongue position, and the postrocalic consonant $/ r /$ was always produced with central hump position. The difference between the results in this study and Kurath's opinion, may be because Zurath did not base his opinion on empirical data, or because the number of stimuli in this study was too small to warrant a valid conclusion.

\section{Phonetic Context}

The tongue positions of the two consonant /r/ stimuli immediately preceding or following a low back vowel were compared with the tongue positions of the two consonant $\mid \dot{r} /$ st Imuli immediately preceding or following two high front vowels, and there was a substantial difference found between the tongue positions in these opposite phonetic contexts. A higher percentage of subjects used retroflex tongue position in the low back phonetic context and central hump position in the two high front phonetic contexts. 
By analyzing the tongue movements involved, it can be theorized why this occurred. The stimulus/Ir/ begins with the front of the tongue high in the oral cavity. To produce the central hump / $/$ following this sound requires a slight retraction of the tongue, slight raising of the back of the tongue, and slight. lowering of the front of the tongue. To produce the retroflex /r/ following /I/ requires a greater adjustment of the tongue, as the tip of the tongue must be raised from a very low position in the mouth to a high one. The same type of tongue movements occur in the stimulus $/ r i /$. Although the $/ r /$ is produced before the high front vowel, the tongue is already beginning to anticipate the movements for the upcoming / $i /$ sound, and assumes the most similar tongue position possible, which would be the central hump.

There has been much support in the literature for the idea that sounds are not isolated units, but are affected by preceding and following sounds to the extent that totally different muscle movements may occur (Curtis, 1953; Shohara, 1939; Stetson, 1951).

Tests of articulation are now beginning to reflect this philosophy that sounds do not occur as discrete elements in initial, medial or final position of words. McDonald (1964) devised the Deep Test of Articulation in which sounds are studied as parts of movement sequences that are influenced by varying phonetic contexts. 
CHAPTER VI

\section{SUMMARY AND IMPIICATIONS}

\section{Summary}

In articulation treatment and diagnosis, it is essential to possess a thorough knowledge of what is "normal" as well as what is "defective" articulation. The / $/ \mathrm{f}$ phoneme is one of the most frequently occurring and most commonly defective sounds. There are two different tongue positions for the $/ x /$ phoneme described in the literature (retroflex and central hump), with many assumptions about which tongue position is "normal" or "most common." None of these assumptions, however, are based on empirical data.

The purpose of this study was to provide some normative data regarding which of the two tongue positions is most common in children who have learned to produce the $/ r /$ phoneme normally with no clinical assistance. Six research questions were posed: (1). Do children produce the / $/$ phoneme more commonly with retroflex or central hump tongue position? (2) Are there sex-related differences? (3) Are there differences in tongue position when the /r/ is used as a consonant or vowel? (4) Are there differences in tongue position when the vocalic $/ r /$ is stressed or unstressed? (5) Are there differences in tongue position 
relating to the position of the /r/ phoneme within a syllable? (6) Does phonetic context affect the tongue position of the / $\mathrm{r} /$ phoneme?

Three hundred white children, 150 males and 150 females, ranging in age from nine to twelve years, were instructed to produce twelve verbal stimuli containing $/ r /$ allophones in various positions within words. Three samples of phonetic context were included in the stimuli. Using a flashlight, the examiner looked into the subject's mouth and made a judgment about tongue position for each response.

The first two research questions were presented in the form of four null hypotheses, and were tested using Chi Square analysis. All four hypotheses were rejected, and therefore it was concluded that:

1. The total population of children tended to use retroflex tongue position more often than central hump.

2. Male subjects tended to use retroflex tongue position more often, and female subjects tended to use central hump more often. The remaining research questions were not tested statistically, but the following trends were apparent from the data:

1. There does not appear to be a substantial difference in tongue position between consonant and 
rocalic / $/ \mathrm{r}$ allophones.

2. There does not appear to be a substantial difference in tongue position between stressed and unstressed vocalic / $r /$ allophones.

3. There does not appear to be a substantial difference in tongue position depending upon the position of the / $r /$ within a syllable.

4. There does appear to be a substantial difference in tongue position between the two phonetic contexts represented in this study.

\section{Implications for Clinic and Future Research}

\section{Clinic}

The findings in this study may provide implications for the treatment of articulation disorders of the /r/ phoneme. Instead of automatically instructing clients in the use of one tongue position, clinicians should evaluate the particular client to determine which tongue position is most efficient for him. Some valuable treatment time may be conserved if the retroflex position is instructed with male clients, and the central hump position with female clients, since these were found to be the most common positions for each sex.

It is further indicated that one tongue position should not necessarily be taught to the client for every phonetic context of the $/ r /$ phoneme. Many of the subjects 
in this study used a combination of both tongue positions, depending upon the phonetic context of the stimulus. If a client is having difficulty with the $/ r /$ in a particular phonetic context, it might prove valuable to instruct in a different tongue position.

\section{$\underline{\text { Research }}$}

It is suggested for future studies of this nature that a larger sample of verbal stimuli could aid in conclusions regarding: the effect of syllable position; the effect of vocalic Vs. consonant allophones; the effect of stressed Vs. unstressed rowels; and the effect of phonetic context, upon tongue position. The small sample of stimuli used in this study severely restricted any interpretations of results which could be generalized.

While the population tested in this study was large, it was confined to upper-midale class white children. Future studies might add children of different races and economic level to provide a more representative sample of subjects. Testing of older age groups might aid in determining if the trend found in this study for males to use more retroflex tongue position and females more central hump position continues into adulthood. A study correlating tongue position of parents and children to determine the effect of inherited predispositions toward one tongue position vs. pure learning might prove valuable.

Further studies also are needed to determine the 
reasons for the results of this study, particularly to discover why there was such a significant sex difference. This study was not designed to discover the reasons for different tongue position use, and further research would be of value in this area. 


\section{SELECTED BIBLIOGRAPHY}

Barnes, G., General American Speech Sounds. Boston: D. C. Heath and Co. (1946).

Berry, M. F. and Eisenson, J., Speech Disorders: Principles and Practices of Therapy. New York: AppletonCentury-Crofts (1956).

Bronstein, A. J., The Pronunciation of American English: An Introduction to Phonetics. New York: AppletonCentury-Crofts (1960).

Carrell, J. and Tiffany, W. R., Phonetics: Theory and Application to Speech Improvement. New York: McGraw-Hill (1960).

Cromwell, H. and Van Dusen, C. R., Oral Approach to Phoenetics. Columbus, Ohio: Charles E. Merrill (1969).

Curtis, J., Systematic research in experimental phonetics: 3. The case for dynamic analysis in acoustic phonetics. J. Speech Hearing Dis., 19, 147-157 (1954).

Curtis, J. F. and Hardy, J. C., A phonetic study of misarticulation of $/ \mathrm{r} /$. J. Speech Hearing Res., 2, 244-257 (1959).

Eisenson, J., The Improvement of Voice and Diction (2nd Ed.). New York: The Macmillan Co. (1968).

Fairbanks, G., Voice and Articulation Drillbook (2nd Ed.). New York: Harper and Bros. (1960).

Fields, V. A. and Bender, J. F., Voice and Diction. New York: The Macmillan Co. (1949).

Fisher, H. B., Improving Voice and Articulation. New York: Houghton Mifflin (1966).

Gordon, M. J. and Wong, H. H., A Manual for Speech Improvement. Englewood Cliffs, New Jersey: Prentice-Hall (1961). 
Gray, G. W., Speech Sound Formation. Chap. in I. E. Travis (Ed.), Handbook of Speech Pathology and Audiology. New York: Appleton-Century-Crofts (1971).

Hahn, E., Lomas, C. W., Hargis, D. E. and Vandraegen, D., Basic Voice Training for Speech. New York: McGrawHiII (1952).

Hall, M. E., Auditory factors in functional articulatory speech defects. J. Exper. Educ., 7, 110-132 (1938).

Hanley, T. D. and Thurman, W. I., Developing Vocal Skills: New York: Holt, Rinehart and Winston (1962).

Heffner, R-M. S., General Phonetics. Madison, Wisconsin: The University of Wisconsin Press (1953).

Henrikson, E. H., An analysis of Wood's articulation index. J. Speech Hearing Dis., 13, 233-235 (1948).

Hibbitt, G. W. and Norman, R. A., Guide to Speech Training: Voice, Articulation and Oral Reading. New York: The Ronald Press (1964).

Hicks, H. G:, Voice and Speech for Effective Communication. Dubuque, Iowa: Wm. C. Brown (1963).

Hockett, C. F., A Course in Modern Linguistics. New York: The Macmilian Co. (1958).

Hultzen, I. S., Symbol for the non-syllabic post-vocalic $R$ of General American. Quart. J. Speech, 34, 189-201 $(1950)$.

Jones, D., The Pronunciation of English. Cambridge: University Press (1958).

Kantner, C. E. and West, R., Phonetics: An Introduction to the Princioles of Phonetic Science from the Point of View of English Speech (Rev. Ed.). New York: Harper and Bros. $(1960)$.

Kenyon, J. S., American Pronunciation (10th Ed.). Ann Arbor, Mich.: George Wahr Pub. Co. (1969).

Kenyon, J. S. and Knott, T. A., A Pronouncing Dictionary of American English. Springfield, Mass.: G. and C. Merriam (1953).

Kurath, H., A Phonology and Prosody of Moderm English. Ann Arbor, Mich.: The University of Michigan Press (1964). 
Iehiste, I., Acoustical Characteristics of Selected English Consonants. Bloomington, Ind.: Indiana University $(1964)$.

Leutenneger, R. R., The Sounds of American English: An Introduction to Phonetics. Chicago: Scott, Foresman and Co. (1963).

Levy, I., Mammen, E. W., and Sonkin, R., Voice and Speech Handbook. Englewood Cliffs, New Jersey: PrenticeHaII (1955).

Iuchsinger, R. and Arnold, G. E., Voice-Speech-Ianguage. Belmont, Cal.: Wadsworth Pub. Co. (1965).

McDonald, E. T., Articulation Testing and Treatment: A Sensory-Motor Approach. Pittsburgh: Stanwix House, Inc. $(1964)$.

Nemoy, E. M., and Davis, S. F., The Correction of Defective Consonant Sounds (2nd Ed.). Magnolia, Mass.: Expression Co. (1954).

Poole, I. Genetic development of articulation of consonant sounds in speech. Elementary English Rev., 2, 159-161 (1934).

Potter, R. K., Kopp, G. A., Kopp, H. G., Visible Speech. New York: Dover Publications $(1966)$.

Prator, C. H., Manual of American English Pronunciation (Rev. Ed. Tew York: Holt, Rinehart and Winston (1957).

Roe, V., and Milisen, R., The effect of maturation upon defective articulation in elementary grades. J. Speech Hearing Dis., 7, 37-45 (1942).

Shohara, H., Significance of overlapping movements in speech. Proceedings of the Second Biennial Central Zone Conference of the American Society for the Hard of Hearing. St. Louis, Missouri (May, 1939). In E. T. MeDonald, Articulation Testing and Treatment: A Sensory-Motor Approach. Pittsburgh: Stanwix House, Inc. (1964).

Stetson, R. H., Motor Phoneties: A Study of Speech Movements in Action (2nd Ed.). Amsterdam: North-Holland Pub. Co. (1951).

Templin, M. C., Speech development in the young child: 3 . The development of certain language skills in children. J. Speech Hearing Dis., 17, 280-285 (1952). 
Thomas, C. K., An Introduction to the Phonetics of American English (2nd Ed.). New York: The Ronald Press (1958).

Travis, I. E., Speech Pathology. New York: D. AppletonCentury $(1931)$.

Van Riper, C., Speech Correction: Principles and Methods (Rev. 4th Ea.). Englewood Cliffs, New Jersey: Prentice-Hall (1963).

Van Riper, C., and Irwin, J. V., Voice and Articulation. Englewood Cliffs, New Jersey: Prentice-Hall (1958).

West, R. W., and Ansberry, M., The Rehabilitation of Speech (4th Ed.). New York: Harper and Row (1968).

Wise, C. M., Applied Phonetics. Englewood Cliffs, New Jersey: Prentice-Hall (1957).

Young, E. H., and Hawk, S. S., Moto-Kinesthetic Speech Training. Stanford, Cal:: Stanford University Press (1955). 